\title{
(3)
}

\section{SENTIDO DE COMUNIDAD Y PERCEPCIÓN DE SEGURIDAD EN BARRIOS DE TALCA: LA PREVENCIÓN COMUNITARIA DEL DELITO.}

\section{Cristina Valenzuela ${ }^{13}$. Oriana Arellano ${ }^{14}$.}

\section{RESUMEN}

El sentido de comunidad es un concepto que cuenta con evidencia teórica y empírica para ser vinculado a la percepción de inseguridad en los barrios. Este estudio se propone determinar el poder predictivo del sentido de comunidad sobre la percepción de inseguridad en dos barrios de la ciudad de Talca: Sector Carlos Trupp y Villa San José de la Florida.

Se observa que el sentido de comunidad no predice la percepción de inseguridad, pero sí los recursos para prevenir la delincuencia. No se presentan diferencias en el sentido de comunidad en ambos barrios. Se discuten las implicancias para la evaluación de programas preventivos a nivel municipal.

Palabras clave: sentido de comunidad, percepción de inseguridad, barrios, programas preventivos, participación comunitaria.

\section{ABSTRACT}

The sense of community is a concept that has sufficient theoretical and empirical evidence to be linked to the perception of insecurity in neighborhoods. This study aims to determine the predictive power of the sense of community over the perception of insecurity in two neighborhoods in the city of Talca: Carlos Trupp and San José de la Florida. Results indicate that the sense of community does not predict the perception of insecurity, yet the resources to prevent crime do it. There are no differences in the levels of sense of community between both neighborhoods. The article discusses the implications of these results for local preventive programs evaluations.

Key words: sense of community, unsafe feeling, neighborhoods, preventive programs, community participation.

13 Cristina Valenzuela Contreras. Psicóloga, Mg. Psicología Social-Comunitaria, Pontificia Universidad Católica de Chile. Miembro Society for community research and action (SCRA). / cvalenzuelac@uautonoma.cl

14 Oriana Arellano Faúndez. Psicóloga social y organizacional. Mg. Psicología social, mención Desarrollo de organizaciones saludables, Universidad de Talca. / oarellanof@uautonoma.cl 


\section{INTRODUCCIÓN ${ }^{15}$}

El sentido de comunidad es un concepto que ocupa un territorio complejo dentro del debate teórico y empírico en las ciencias sociales. En la actualidad destaca su contribución desde el campo disciplinar de la psicología comunitaria, a través de aplicaciones en contextos multiculturales y con un volumen de publicaciones importante en el área.

Sentido de comunidad constituye un constructo validado empíricamente en diversas áreas del conocimiento psicosocial, asociado con el prejuicio ético y la orientación política (Prezza, Zampatti, Pacilli \& Paoliello, 2008), y la participación política (Anderson, 2010). En el ámbito del quehacer comunitario presenta asociaciones con los significados que le otorgan los habitantes a sus comunidades (Mannarini \& Fedi, 2009), entre otros aspectos. Diversas investigaciones han evaluado este constructo en áreas heterogéneas como la aculturación de inmigrantes en países de acogida (Hombrados, Gómez \& Domínguez, 2009), la satisfacción vital en vecindarios (Prezza, Amici, Roberti \& Tedeschi, 2001) y el desarrollo de organizaciones comunitarias (Peterson, Speer, Hughey, Armstead, Schneider, Sheffer, 2008), entre otros procesos y resultados del desarrollo local. Adicionalmente, presenta una relación significativa con el bienestar subje- tivo, ya que se asocia positivamente con un óptimo estado de salud mental en las personas, especialmente en adolescentes (Pretty, Conroy, Dugay, Fowler, \& Williams, 1996). Sarason (1974), define el sentido de comunidad como una experiencia subjetiva de pertenencia a una colectividad mayor, formando parte de una red de relaciones de apoyo mutuo en la que se puede confiar.

Respecto al origen del concepto sentido de comunidad, merecen atención las primeras distinciones ofrecidas por el sociólogo alemán Ferdinand Tönnies, 1889, citado en Álvaro (2010), respecto a comunidad y sociedad (Gemeinschaft - Gesellschaft) y a la naturaleza del vínculo social que se origina en cada una de ellas. En las relaciones comunitarias sobresale una cualidad personal, afectiva, familiar y tribal, representando un modo de estructuración social que entra en oposición con las relaciones sociales, modo de estructuración social que nace en el seno de la industrialización y que dota a las relaciones de un carácter instrumental, táctico, estratégico y cruzado por la valoración de la función que las personas ocupan en la estructura social ${ }^{16}$ (Álvaro, 2010). Así cobra importancia la evaluación de la percepción que las personas tienen de los componentes comunitarios de la realidad social.

15 Este artículo contiene una nueva propuesta de investigación, que emerge a partir de investigación previa conducente al grado de psicólogo de los alumnos Carmen Gloria Corvalán, Romina Najle y Pablo Cisternas, en la Escuela de Psicología de la Universidad Autónoma de Chile. Cristina Valenzuela, ejerció como profesora guía de esta tesis.

16 Este elemento de oposición, explícito en la propuesta de Tönnies, introduce una tensión a las prácticas de intervención social que promueven formas de organización social comunitaria, sea a partir de una lógica instrumental o desde el exterior. 
En el campo de lo psicosocial, el concepto es acuñado por McMillan \& Chavis (1986), popularizando la teoría multidimensional de mayor impacto para la ciencia comunitaria, tanto en los debates teóricos como en la propuesta de instrumentos de medición. Estos autores proponen que el sentido de comunidad está compuesto por cuatro dimensiones:

Pertenencia o Membrecía. Consiste en el sentimiento de ser parte de la red de relaciones sociales de un grupo. La membrecía contribuye a crear en el individuo un sentido que le permite diferenciar quien es parte de la comunidad y quien no lo es.

Influencia. Es un concepto bidireccional. En una dirección está la noción de que por un miembro estar atraído al grupo, él o ella debe tener alguna influencia sobre lo que el grupo hace; y en la otra, la cohesión depende de la capacidad de un grupo para influir sobre sus miembros. Esta dimensión cobra especial relevancia cuando se liga el sentido de comunidad a la participación, es decir: la participación en la comunidad posibilita ejercer una influencia sobre ésta o ser influido por ella.

Integración y satisfacción de necesidades. Este elemento tiene que ver, en primer lugar, con los valores compartidos por los miembros del grupo y segundo, con el intercambio de recursos que se establece para satisfacer las necesidades de los integrantes. En el ámbito de este estudio, se puede ejemplificar el primero con el compromiso de un vecindario en combatir la delincuencia y el segundo, con el compartir elementos de seguridad o "cuidarse unos a otros" (Maya, 2004).

Conexión emocional compartida. Finalmente, los miembros del grupo reconocen la existencia de un lazo compartido. Este vínculo es el resultado del contacto positivo prolongado y de participar de experiencias y una historia en común (Maya, 2004).

McMillan \& Chavis (1986) refieren que el elemento sentido de comunidad apunta al convencimiento que los miembros tienen que han compartido y compartirán una historia común, lugares, tiempo juntos y experiencias similares.

\section{Sentido de comunidad en barrios}

Se ha investigado el sentido de comunidad mediante el nivel de análisis de barrio (Prezza et al., 2001), a través del estudio de las actitudes que poseen los habitantes hacia sus barrios (Brodsky, O'campo \& Aronson, 1999; Kingston, Mitchell, Florin \& Stevenson, 1999), considerado un componente ventajoso para comprender el desarrollo de los vecindarios en Chile y especialmente la configuración y clima social de los barrios de la ciudad de Talca.

Este tipo de estudios presenta alta relevancia para comprender cómo la percepción de recursos psicosociales en el barrio puede tener un efecto significativo sobre la prevención de conductas de riesgo y problemas psicosociales, tales como la prevención de la delincuencia (Núñez, Tocornal \& 
Henríquez, 2012), entre otros determinantes individuales y del entorno residencial. Estudios en barrios del gran Santiago han documentado cómo la percepción de inseguridad en el barrio posee una fuerte asociación con los vínculos relacionales entre vecinos.

El sentido de comunidad ha sido ampliamente utilizado para comprender el efecto que tiene la percepción de los vecinos sobre la presencia y magnitud de los problemas sociales, junto con el aumento de la participación ciudadana para su resolución (Kingston et al., 1999).

Se ha documentado que, al interior del mismo barrio, las percepciones sobre las condiciones del vecindario, el comportamiento de reciprocidad entre vecinos y el nivel de participación en organizaciones comunitarias, es más parecido entre vecinos del mismo barrio que entre vecinos de barrios diferentes. Ohmer (2010), informa que en barrios de menores recursos se observa una relación significativa entre el sentido de autoeficacia personal y colectiva (e.g. posibilidad de influir en las decisiones que toman los vecinos) con el sentido de comunidad percibido.

Lo comunitario para Núñez et al. (2012), representa una serie de atributos del conjunto como cualidades de las dinámicas relacionales entre vecinos que configuran una identidad residencial, integrando componentes físicos y simbólicos. Dentro de los componentes simbólicos es posible situar el sentido de comunidad como un atributo relacional, el que se construye en base a interacciones recíprocas al interior de los barrios.

\section{Sentido de comunidad y percepción de inseguridad ante el delito}

Este recurso simbólico, configurado en la interacción entre vecinos, presenta ventajas teóricas y aplicadas de amplia pertinencia para entender dinámicas individuales y colectivas, como el temor a otros o temor a la delincuencia (Núñez et al., 2012).

La percepción de inseguridad ante el delito constituye un asunto de interés público, formando parte de la agenda programática de diferentes gobiernos, al ubicarse entre las principales preocupaciones de los chilenos. Se ha definido como percepción subjetiva de amenaza potencial de ser víctima de un delito. Sin embargo, esta percepción no constituye una manifestación puramente mental o psicológica, sino que está influida o mediada por elementos contextuales, tal como el grado de integración social o factores individuales, tales como el género o el nivel socioeconómico (Núñez et al., 2012; Fundación Paz Ciudadana, 2011; Varela \& Shwaderer, 2010).

La percepción de inseguridad constituye ante todo una vivencia de miedo subjetivo, de naturaleza cambiante y permeable al impacto de los medios de comunicación y la manipulación de las agendas políticas. Como indican Skogan \& Maxfield (1981), este tema constituye un problema urbano, derivado de los vínculos comunitarios erosionados, manifestación 
residual de una urbe que produce y reproduce patologías sociales (Vozmediano, 2010).

En palabras de Vozmediano (2010, citando a Fitzerld, 2008), el miedo a la delincuencia se "mide típicamente como el nivel de seguridad percibido en distintas situaciones, por ejemplo, en la casa o la comunidad". Se ha reportado empíricamente que el sentido de comunidad está asociado a indicadores de miedo y crimen.

\section{Aspectos metodológicos}

Tradicionalmente el estudio sobre percepción de inseguridad se ha formulado a través de una metodología de encuesta, como ha sido el caso de la Encuesta Nacional de Seguridad Urbana, diseñada con el propósito de obtener información a nivel nacional, regional y comunal sobre la percepción de inseguridad y la victimización de personas y hogares, caracterizando las situaciones en que se producen los delitos y la percepción de la ciudadanía ante estos delitos (Ministerio del Interior y Seguridad Pública, 2012).

Una crítica habitual a este tipo de metodología es la sobreestimación del miedo al delito, producto que algunos de sus reactivos integran medidas operacionalizadas a través de la intensidad y no de la frecuencia de exposición, aspecto que puede estar sobrerepresentando elementos persuasivos incorporados en los medios de comunicación y cambios socioculturales (Vozmediano, 2010).
Si bien este artículo no tiene por objetivo discutir las implicancias metodológicas de la medición de la percepción de inseguridad, si propone la importancia de contar con la estimación de medidas contextualizadas, de tipo cualitativo-subjetivo, de la percepción de inseguridad. La actual encuesta ENUSC recoge este tipo de elementos contextuales relacionales como medidas preventivas adoptadas entre vecinos. ${ }^{17}$ Sin embargo, este estudio propone la integración de medidas cualitativas observadas a través de la interacción entre vecinos para proporcionar información que cuente con suficiente validez ecológica y contextualizada a las percepciones subjetivas de los vecinos de ambos barrios.

Por su parte, el sentido de comunidad ha sido evaluado habitualmente a través del índice de Mc Millan \& Chavis (1986). Pero, en la literatura se reportan otras estrategias de medición basadas en componentes no sólo simbólicos (e.g. mutua influencia) sino también territoriales (e.g. clima social percibido del barrio). Estas estrategias de medición cuentan con suficiente respaldo empírico, por ejemplo, la propuesta de medición desarrollada en pequeños barrios, ciudades y metrópolis italianas (Prezza, Pacilli, Barbaranelli \& Zampatti, 2009) que integra componentes territoriales.

17 La pregunta № 75 de la actual ENUSC (Ministerio del Interior y Seguridad Pública, 2012) incorpora la observación sobre las prácticas contextuales que los vecinos desarrollan para protegerse del delito. 
En el caso chileno y para efectos de esta investigación, se utilizan las medidas propuestas por Buzó (2011), quién desarrolla una versión de la escala de sentido de comunidad adaptada al barrio, integrando a ésta una dimensión cualitativa elaborada a partir de datos verbales de este estudio.

\section{Contextualización de los barrios es- tudiados}

En Talca, la oferta pública dirigida a la prevención de la delincuencia en el periodo en que se recogen los datos -2010 y 2011-, se focalizó, principalmente, en la instalación de alarmas comunitarias en diversos sectores de la ciudad. Los proyectos realizados incorporaron un diagnóstico situacional del delito y los barrios fueron priorizados por el Ministerio del Interior según sus niveles de victimización y percepción de inseguridad ante el delito. ${ }^{18}$
Ambos barrios constituyen experiencias pioneras de inserción de este tipo de estrategias preventivas municipales en la comuna. Sin embargo, se desconoce los niveles de sentido de comunidad de ambos barrios y si este componente presenta relación con la percepción de inseguridad ante el delito de sus habitantes.

En suma, este estudio se propone la integración de una dimensión cualitativa a las medidas tradicionales de percepción de inseguridad y sentido de comunidad en dos casos significativos de la ciudad de Talca. Lo anterior se justifica por la ausencia de indicadores específicos que incorporen elementos territoriales y la mayor pertinencia y sensibilidad de indicadores cualitativos para el estudio del temor colectivo y las escalas disponibles de sentido de comunidad'19. Además, se propone determinar la capacidad predictiva del sentido de comunidad sobre la percepción de inseguridad ante el delito, y comparar los niveles de sentido de comunidad y percepción de inseguridad ante el delito en ambos barrios.

\footnotetext{
18 Entre estos barrios se encuentran las poblaciones Carlos Trupp ( 924 alarmas) y San José de la Florida (400 alarmas). Ellos representan conjuntos habitacionales heterogéneos, pero que comparten este tipo de acciones preventivas ejecutadas entre los años 2009 y 2010. La Villa San José de La Florida es un conjunto habitacional perteneciente al Cuadrante № 6 de Seguridad Policial, ubicada al Sur Poniente de la ciudad de Talca. Posee una población residente de 30.250 habitantes. El tipo de emplazamiento y crecimiento urbano es segregado. Las primeras etapas de la villa tienen 11 años aproximados de antigüedad y se hacía necesario implementar este tipo de proyecto debido al creciente aumento de la victimización y percepción de inseguridad de la población. Diagnóstico Proyecto Sistema de Alarmas Comunitarias en la Villa San José de la Florida - 2010 (Oficina comunal de seguridad ciudadana, 2010). Por su parte, la Población Carlos Trupp constituye una de las poblaciones emblemáticas de la comuna. Conformada en sus inicios por habitantes provenientes de campamentos y conjuntos de allegados, se caracteriza por un alto nivel de organización social y niveles crecientes de participación en organizaciones comunitarias. Limita con las poblaciones San Luis, San Antonio, San Miguel del Piduco y Bandejón Central. Está ubicada en un Cuadrante de Seguridad Preventiva de Carabineros que cubre un número aproximado de 8.153 personas residentes y una población flotante que no supera las 1.000 personas. Tiene más de 150 locales de comercio menor en su interior. Dispone de diversas instituciones, tales como jardines JUNJ, establecimientos educacionales, centros de salud, radio comunitaria, fundaciones, entre otras. Así también, posee espacios comunitarios como recintos deportivos, sedes comunitarias, espacios públicos deteriorados, sitios eriazos y casas abandonadas (Oficina comunal de seguridad ciudadana, 2010).

19 Los datos aquí presentados constituyen una sección de la tesis de pregrado, en que la autora principal de este artículo ejerció como guía de tesis.
} 


\section{MARCO TEÓRICO}

Dammert (2007) plantea que para disminuir la sensación de inseguridad es necesario atender a los factores que erosionan la participación y debilitan el tejido social, por un lado, reduciendo obstáculos administrativos y burocráticos que dificultan la implementación de programas preventivos, y por otro, generando reformas estructurales a los organismos encargados de dichos programas.

Al analizar las estrategias de intervención en seguridad ciudadana, se observa que ellas se focalizan en la recuperación del uso del espacio público como lugar de encuentro y sociabilidad. Tal como se plantea en la Estrategia Nacional de Seguridad Ciudadana del Ministerio del Interior y Seguridad Pública, la consecuencia más práctica de la percepción de inseguridad es la autorestricción de los individuos a ámbitos privados, restringiendo sus horas, e incluso autolimitando la interacción con sus semejantes. Fortalecer la confianza personal e institucional es un mecanismo necesario para contrarrestar la "cultura del resguardo", la cual está basada en el temor de poder ser atacados/as "en cualquier momento, en cualquier lugar y por cualquier persona" (Santillán, 2007).

Como ha sido analizado en diversos estudios y encuestas de opinión, la percepción de inseguridad es superior en los sectores de niveles socioeconómicos más bajos. Es así como Fundación Paz Ciudadana (2011b) señala que ese año las personas de hogares de grupo socioeco- nómico bajo destacan con un alto porcentaje de temor $(19,3 \%)$, lo que demostraría un foco importante de inseguridad en un segmento que reúne alrededor del $40 \%$ de los hogares de nuestro país. El predominio de estos niveles de temor en población de sectores socioeconómicos medio y bajo, orientó la selección de los barrios estudiados en la ciudad de Talca, ya que representan estratos socioeconómicos comúnmente afectados por niveles elevados de victimización o percepción de inseguridad.

Se ha indicado en la literatura psicosocial que la percepción de inseguridad al delito suele estar asociado con determinantes individuales, sociales y territoriales (Núñez et al., 2012). Estos autores destacan, entre otros aspectos, la confianza e interacción entre vecinos como variables relacionadas significativamente con la percepción de seguridad, junto con aspectos históricos como la antigüedad del barrio y la presencia de programas de seguridad ciudadana a nivel del territorio.

Frühling y Sandoval (1997), señalan que los sectores con mayor índice de vulnerabilidad al delito son los más pobres y los que corresponden a poblaciones nuevas o provenientes de erradicaciones ocurridas durante los años ochenta. En estos casos se producirían la acumulación de personas carentes de recursos y de trabajo, que son desconocidas entre sí. Esto dificulta la educación y el control sobre los menores, existiendo un clima propicio para disputas y para la utilización de la violencia en la resolución de conflictos. 
La percepción de riesgo está influenciada, por ejemplo, por determinantes personales como el género o la edad, experiencias de victimización pasada, el haber sido o no testigo de hechos delictivos -ya sea de forma directa o mediante la influencia de los medios de comunicación masivos-, la confianza que se tiene en los demás y en las instituciones de justicia, y el nivel de desorden del entorno en el que se desenvuelven (Frühling y Sandoval, 1997).
Estrategias preventivas a nivel nacional

En la actualidad, la institucionalidad en Chile, encargada de abordar el tema de la seguridad y prevención situacional del delito es la Subsecretaria de Prevención del Delito. Dentro de ésta, la Unidad de Prevención del delito tiene por objetivo planificar, diseñar, supervisar, controlar y evaluar todas las acciones a nivel nacional, regional y local, promoviendo las definiciones de una política pública en seguridad urbana.

Dentro de los proyectos implementados en la materia por esta Unidad se encuentran: 
Tabla $n^{\circ} 1$. Programas en prevención situacional del Delito en el Barrio

\begin{tabular}{|c|c|c|}
\hline $\begin{array}{l}\text { PROYECTO: } \\
\text { Plan Chile Seguro }\end{array}$ & OBJETIVO & $\begin{array}{l}\text { ÁMBITO DE } \\
\text { APLICACIÓN }\end{array}$ \\
\hline $\begin{array}{l}\text { Diseño Urbano Seguro en } \\
\text { la Reconstrucción }\end{array}$ & $\begin{array}{l}\text { Contribuir a la planificación y } \\
\text { reconstrucción de las ciudades } \\
\text { y localidades afectadas por } \\
\text { el terremoto, mediante la } \\
\text { incorporación de variables de } \\
\text { prevención situacional en el } \\
\text { desarrollo urbano y habitacional, } \\
\text { en los Planes Maestros de } \\
\text { Reconstrucción Sustentable } \\
\text { impulsados por MINVU, así } \\
\text { como otros Instrumentos de } \\
\text { Planificación Territorial. }\end{array}$ & $\begin{array}{l}\text { Escala ciudad, } \\
\text { barrio y vivienda. }\end{array}$ \\
\hline $\begin{array}{l}\text { Diseño Urbano Seguro en } \\
\text { Bienes de Uso Público }\end{array}$ & $\begin{array}{l}\text { Incorporar variables de } \\
\text { prevención situacional en } \\
\text { procesos de planificación y } \\
\text { diseño de la edificación publica, } \\
\text { mediante transferencia a } \\
\text { instituciones responsables de la } \\
\text { planificación urbana y diseño de } \\
\text { infraestructura pública. }\end{array}$ & $\begin{array}{l}\text { Edificación } \\
\text { pública, espacios } \\
\text { educativos. }\end{array}$ \\
\hline $\begin{array}{l}\text { Certificación Seguridad } \\
\text { Residencial }\end{array}$ & $\begin{array}{l}\text { Desarrollar un sistema que } \\
\text { certifique la seguridad de } \\
\text { las viviendas, estableciendo } \\
\text { estándares mínimos de } \\
\text { prevención en conjuntos } \\
\text { residenciales nuevos y existentes, } \\
\text { que aumenten la seguridad de } \\
\text { las viviendas y disminuyan la } \\
\text { oportunidad de robo. }\end{array}$ & $\begin{array}{l}\text { Vivienda social, } \\
\text { vivienda privada. }\end{array}$ \\
\hline $\begin{array}{l}\text { Diseño Urbano Seguro en } \\
\text { el Comercio }\end{array}$ & $\begin{array}{l}\text { Incorporar estándares mínimos } \\
\text { de prevención del delito y la } \\
\text { violencia en locales y barrios } \\
\text { comerciales, mediante la } \\
\text { transferencia técnica, difusión, } \\
\text { implementación y evaluación } \\
\text { de medidas preventivas } \\
\text { y de seguridad, orientada } \\
\text { principalmente a locatarios, } \\
\text { asociaciones gremiales y } \\
\text { municipalidades. }\end{array}$ & $\begin{array}{l}\text { Sectores } \\
\text { comerciales, } \\
\text { tiendas } \\
\text { minoristas, } \\
\text { sectores comercio } \\
\text { nocturno. }\end{array}$ \\
\hline
\end{tabular}

Fuente: Elaboración propia, a partir de revisión página web institucional Subsecretaria de Prevención del Delito. 
De manera complementaria a los programas y planes mencionados se encuentran áreas de intervención de la Subsecretaría de Prevención del Delito, entre los que destacan el Barrio en Paz Residencial, Barrio en Paz Comercial, Fondo Nacional de Seguridad Pública, así como otros proyectos específicos.

Estrategias preventivas a nivel municipal

Desde el ámbito municipal, la Ley Orgánica Constitucional de Municipalidades señala en su Artículo 4 letra j, que:

"Las municipalidades, en el ámbito de su territorio, podrán desarrollar, directamente o con otros órganos de la Administración del Estado, funciones relacionadas con el apoyo y el fomento de medidas de prevención en materia de seguridad ciudadana y colaborar en su implementación, sin perjuicio de lo dispuesto en el inciso tercero del artículo 90 de la Constitución Política".

Para llevar a cabo estas funciones, las municipalidades pueden incluir los temas de seguridad ciudadana en su respectivo Plan Comunal de DesarroIlo (Pladeco) y en su Presupuesto Municipal.

Uno de los precursores en materia de prevención y seguridad ciudadana en el barrio es el Programa Comuna Segura, iniciativa que fue inspirada en el modelo inglés de prevención, safer cities, que fue implementado en setenta comunas del país. Según Dammert (2004), corresponde a una iniciativa gubernamental nacida el año 2000, que buscaba fortalecer la seguridad ciudadana a nivel local y comunitario, teniendo como pilares centrales la participación comunitaria y el desarrollo de redes sociales participativas en la prevención de la delincuencia, así como el desarrollo del capital social local.

Actualmente, a nivel local se ha implementado el denominado Plan Comunal de Seguridad Ciudadana. Los diversos planes comunales se enmarcan dentro de la Política Nacional de Seguridad Pública, que entrega un importante rol a la comunidad y a la articulación entre actores, con el fin de implementar estrategias de promoción de la participación comunitaria como clave en el desarrollo de condiciones de seguridad, tanto objetivas como subjetivas.

Este estudio se centra en evaluar dos barrios que han sido receptores de estrategias preventivas de alarmas comunitarias, las que se basan en la interacción recurrente, comprometida y cooperativa de los vecinos para disminuir la probabilidad de delito en sus sectores de residencia. 


\section{DISEÑO DEL ESTUDIO REALIZADO}

A continuación se informan los parámetros constitutivos del diseño del estudio empírico realizado y factores asociados a su implementación.

\section{Objetivos del estudio}

a. Explorar empíricamente la dimensionalidad de la percepción de inseguridad ante el delito y el sentido de comunidad en la Villa San José de La Florida y Población Carlos Trupp, de Talca.

b. Describir las percepciones sobre inseguridad en el barrio y las cualidades del sentido de comunidad desde la perspectiva de los habitantes de ambos asentamientos.

c. Diferenciar los niveles de sentido de comunidad en ambos asentamientos.

d. Determinar las diferencias en los niveles de percepción de inseguridad en sus dimensiones 'percepción de inseguridad en el barrio' y 'recursos para afrontar la delincuencia presente' entre los habitantes de ambos asentamientos.

e. Predecir la percepción de inseguridad a través de un modelo de acción conjunta entre las dimensiones del sentido de comunidad que se presentan en ambos asentamientos.

\section{Diseño y tipo de estudio}

Este estudio integró un diseño mixto de investigación de tipo triangulado y exploratorio (Creswell \& PlanoClark, 2007). Poseyó la cualidad de ser triangulado, ya que estructura una recolección de datos cualitativos para facilitar la complementariedad en la comprensión del problema de investigación: la percepción de inseguridad y el sentido de comunidad. En el caso de la cualidad exploratoria, este diseño es útil cuando se requiere identificar variables importantes para estudiarlas cuantitativamente, o bien cuando las variables son desconocidas. En este caso las dimensiones territoriales de la percepción de inseguridad y sentido de comunidad fueron recogidas a través de procedimientos cualitativos para luego ser integradas al instrumento de medición de percepción de inseguridad y explorada su contribución a la estructura de dimensiones a través del análisis factorial.

En relación a la metodología cualitativa, este estudio correspondió a un tipo de estudio descriptivo de contenido, el cual constituye uno de los procedimientos clásicos para analizar el material textual (Flick, 2004).

La metodología cuantitativa correspondió al tipo de estudio correlacional de diseño no experimental transeccional, debido a que el objetivo general fue determinar la relación y el poder predictivo entre las variables centrales del estudio. 


\section{Muestreo}

En la sección cualitativa del estudio se empleó un mapping o mapeo. Esta técnica permite introducirse en un territorio desconocido para acceder a las representaciones y prácticas colectivas. Se desarrolla un acercamiento en cada comunidad aproximándose a la realidad social del objeto de estudio, de forma de conocer aspectos propios de estos sectores, tales como líderes de juntas vecinales, lugares en donde se reúnen y presencia de organizaciones comunitarias. Se desarrollaron dos tipos de muestreo: el muestreo de casos de informantes clave, en el que se identifica a los líderes de cada sector y el muestreo por conveniencia, orientado por una finalidad práctica de acceso a los participantes.

En la sección cuantitativa de este estudio, la muestra utilizada correspondió al tipo no probabilístico intencionado. ${ }^{20}$ Los criterios de inclusión incluyeron la incorporación de mujeres y hombres, residentes actuales de la vivienda (al menos 1 año), mayores de 18 años, en cuyo hogar haya sido instalada una alarma comunitaria en los programas preventivos insertos en ambos barrios.

\section{Muestra y participantes}

La muestra de la sección cualitativa previa de este estudio quedó conformada por 6 vecinos/as de cada barrio, que participaron de 4 entrevistas semi-estructuradas y un grupo focal. La muestra de la etapa de aplicación de instrumentos estandarizados fue conformada por habitantes de la población Carlos Trupp ( $\mathrm{N=106}$ ) y la Villa San José de la Florida $(\mathrm{N}=120)$. El total de encuestados correspondió a 226 participantes.

Sus edades fluctuaron entre los 31 y 56 años. La distribución de los sexos de los participantes no resulta homogénea, es así que las mujeres representan un $66,5 \%$ y los hombres el $33,4 \%$ de los participantes. ${ }^{21}$ En cuanto al estado civil, la mayor parte de los participantes son casados, con un $64,2 \%$ del total, mientras que los convivientes alcanzan solo el 8,8, \%. La cantidad de personas que habitan en el hogar del encuestado suman, en su mayoría, de 3 a 4 personas.

El nivel de escolaridad máximo alcanzado en la muestra corresponde, en su mayoría, a enseñanza media completa, con un $34,1 \%$. Sin embargo, al considerar los puntajes de las poblaciones por separado, se aprecia que en la población Carlos Trupp la mayoría de los encuestados no ha completado la enseñanza media, mientras que en la Villa San José de La Florida la mayoría la constituyen quienes han finalizado cuarto medio y alcanzado estudios superiores.

20 Si bien inicialmente se contempló hacer un muestreo probabilístico y por conglomerados, la dificultad de acceso a los participantes impidió el desarrollo de este tipo de muestreo.

21 Este hecho puede convertirse en un limitante para el estudio, considerando que el género femenino quedó sobre representada. 
El nivel socioeconómico predominante en los encuestados es el C3 con un $36,0 \%$, siendo seguido de cerca por el grupo C2 que posee un 27,6\%; ambos conforman el $63,6 \%$ del total muestral. ${ }^{22}$ En relación con la cantidad de años viviendo en el sector los participantes de Carlos Trupp promedian más de 10 años viviendo en el sector; en cambio, en San José de La Florida tienen un promedio entre 6 a 10 años de residentes. 
Tabla n². Caracterización socio demográfica muestra estudiada.

\begin{tabular}{|c|c|c|c|c|c|c|c|}
\hline \multirow{2}{*}{\multicolumn{2}{|c|}{ Característica Sociodemográfica }} & \multicolumn{2}{|c|}{ CARLOS TRUPP } & \multicolumn{2}{|c|}{ SAN JOSÉ } & \multicolumn{2}{|c|}{ GENERAL } \\
\hline & & Frecuencia & $\%$ & Frecuencia & $\%$ & $n^{\circ}$ total & \%total \\
\hline \multicolumn{2}{|c|}{ Número de participantes } & 106 & 46,9 & 120 & 53,1 & 226 & 100,0 \\
\hline \multirow{3}{*}{ 롫 } & Femenino & 70 & 47,0 & 79 & 53,0 & 149 & 66,5 \\
\hline & Masculino & 35 & 46,6 & 40 & 53,3 & 75 & 33,4 \\
\hline & & & & & & 224 & 100,0 \\
\hline \multirow{6}{*}{ 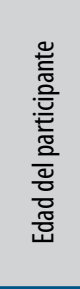 } & 18 a 30 & 14 & 42,4 & 19 & 58 & 33 & 15,3 \\
\hline & 31 a 43 & 18 & 24,3 & 56 & 75,6 & 74 & 34,3 \\
\hline & 44 a 56 & 22 & 44,9 & 27 & 55,1 & 49 & 22,7 \\
\hline & 57 a 69 & 34 & 77,2 & 10 & 22,7 & 44 & 20,4 \\
\hline & 70 a 82 & 10 & 62,5 & 6 & 37,5 & 16 & 7,4 \\
\hline & & & & & & 216 & 100,0 \\
\hline \multirow{6}{*}{ 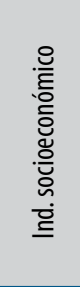 } & $\mathrm{E}$ & 4 & 100,0 & 0 & 0,0 & 4 & 2,0 \\
\hline & D & 29 & 87,8 & 4 & 12,1 & 33 & 16,3 \\
\hline & $\mathrm{C} 3$ & 38 & 52,0 & 35 & 47,9 & 73 & 36,0 \\
\hline & $\mathrm{C} 2$ & 11 & 19,6 & 45 & 80,4 & 56 & 27,6 \\
\hline & $\mathrm{ABC1}$ & 4 & 10,8 & 33 & 89,2 & 37 & 18,2 \\
\hline & & & & & & 203 & 100,0 \\
\hline \multirow{9}{*}{ 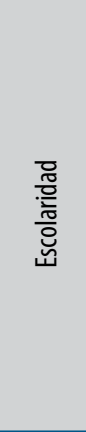 } & Sin estudios & 2 & 100,0 & 0 & 0 & 2 & 0,9 \\
\hline & Básica incompleta & 22 & 81,5 & 5 & 18,5 & 27 & 11,9 \\
\hline & Básica completa & 21 & 91,3 & 2 & 8,7 & 23 & 10,2 \\
\hline & Media incompleta & 19 & 55,9 & 15 & 44,1 & 34 & 15,0 \\
\hline & Media completa & 32 & 41,6 & 45 & 58,4 & 77 & 34,1 \\
\hline & Técnica incompleta & 2 & 22,2 & 7 & 77,8 & 9 & 4,0 \\
\hline & Téc. comp. o Univ. incomp. & 4 & 14,3 & 24 & 85,7 & 28 & 12,4 \\
\hline & Universitaria & 4 & 15,4 & 26 & 84,6 & 26 & 11,5 \\
\hline & & & & & & 266 & 100,0 \\
\hline \multirow{4}{*}{ 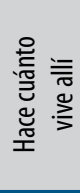 } & $2 \mathrm{a} 6$ años & 11 & 21,6 & 40 & 78,4 & 51 & 25,0 \\
\hline & 6 a 10 años & 5 & 9,6 & 47 & 90,4 & 52 & 26,0 \\
\hline & Más de 10 años & 70 & 70,0 & 30 & 30,0 & 100 & 49,0 \\
\hline & & & & & & 203 & 100,0 \\
\hline \multirow{4}{*}{ 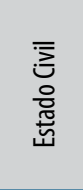 } & Soltero(a) & 28 & 47,5 & 31 & 52,5 & 59 & 26,3 \\
\hline & Casado(a) & 69 & 47,6 & 76 & 52,4 & 145 & 64,7 \\
\hline & Conviviente & 7 & 35,0 & 13 & 65,0 & 20 & 8,9 \\
\hline & & & & & & 224 & 100,0 \\
\hline \multirow{5}{*}{ 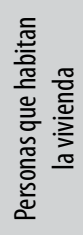 } & 1 a 2 personas & 26 & 61,9 & 16 & 38,1 & 42 & 18,6 \\
\hline & 3 a 4 personas & 59 & 47,8 & 74 & 52,4 & 124 & 54,9 \\
\hline & 5 a 6 personas & 22 & 45,8 & 26 & 54,2 & 48 & 21,2 \\
\hline & 70 más personas & 8 & 66,7 & 4 & 33,3 & 12 & 5,3 \\
\hline & & & & & & 226 & 100,0 \\
\hline
\end{tabular}




\section{Instrumentos}

Instrumento de percepción de inseguridad. Para la medición de percepción de inseguridad se modificó un instrumento elaborado a partir de preguntas obtenidas desde el módulo Inseguridad y Reacción frente al Delito, correspondiente a la Encuesta Nacional Urbana de Seguridad Ciudadana (Ministerio del Interior y Seguridad Pública, 2010), la que se complementó, al igual que la variable sentido de comunidad, con ítems obtenidos desde percepciones de los habitantes de los barrios seleccionados.

Instrumento de Sentido de comunidad. La escala utilizada corresponde al Índice de Sentido de Comunidad adaptado a Barrio, el cual fue creado para la realidad chilena. La escala corresponde a una versión modificada por Buzó (2011), teniendo a la vista el índice chileno de sentido de comunidad que McMillan y Chavis (1986) presentan en su modelo para el desarrollo de una comprensión multidimensional del sentido de comunidad. Este instrumento está compuesto de 12 reactivos relacionados con el lugar en donde vive el entrevistado, con una escala tipo Likert de cuatro puntos, como sigue a continuación con valores que oscilan entre $\mathrm{Nada}$ $=0$; Algo $=1$; Mucho $=2$; Completamente $=3$. Dicho instrumento fue modificado en fraseo y complementado con ítems obtenidos de las la sección cualitativa del estudio previo, quedando su versión final constituida por 20 ítems.

\section{Validez de escalas}

Para evaluar la dimensionalidad tanto del constructo sentido de comunidad (Tabla 3, Anexo 1) como el de percepción de inseguridad (Tabla 4, Anexo 2), se realizó un análisis factorial exploratorio ya que la literatura sugiere la existencia de diferentes dimensiones del concepto. Se integró a este análisis una $5^{\circ}$ dimensión, elaborada a partir del estudio cualitativo que se describirá en los resultados.

Para la percepción de inseguridad se considera la existencia de al menos dos dimensiones que están relacionadas. Por una parte, características particulares de ambos barrios en relación a la percepción de inseguridad y por otra, los recursos para hacer frente a la delincuencia (dimensión extraída del estudio cualitativo previo). Esta distinción es fundamental para construir el modelo de medición de las variables y por consiguiente, la o las escalas en la investigación. EI análisis factorial exploratorio revela la existencia de factores latentes a las variables que explican la covarianza entre ellas (Cudeck, 2000, citado en Martínez y Silva, 2007) y es un método parsimonioso para evaluar validez factorial.

Los 20 ítems o variables de medición de cada uno de los constructos -sentido de comunidad y percepción de inseguridad- se sometieron a un análisis factorial, usando el método de extracción de ejes principales y rotación oblicua (las variables se suponen correlacionadas). De acuerdo al análisis factorial propuesto para sentido de comunidad, se trabajó en 
una primera oportunidad con un intento por hacer rotar los ítems en 5 factores, luego en 4 y por último, se forzaron en tan sólo en tres factores. Asimismo, se pudo constatar que en el análisis factorial de la variable independiente sentido de comunidad, las comunalidades más altas Ilegan hasta un \% de ,933 mientras que las más bajas son de un \% de , 161 .

\section{Confiabilidad}

Para medir la consistencia interna de ambos cuestionarios se realizó un análisis de fiabilidad, para obtener el índice de consistencia interna. Los resultados fueron: primero, para el cuestionario de sentido de comunidad de 20 reactivos, a .86; y segundo, para el cuestionario de 20 reactivos de percepción de inseguridad, éste es fiable, con un a .61 .

\section{Proceso de análisis de datos}

Desde la perspectiva cualitativa y tras la transcripción íntegra de entrevistas y grupo focal, se procedió a segmentar la información en categorías descriptivas para finalizar con la categorización de segundo orden, en la cual se interrelacionan las categorías descriptivas identificadas en el paso anterior. Posteriormente, se utilizó la táctica de agrupación que según Sandoval (1996) "es un proceso de categorización y ordenamiento reiterativo o repetitivo, de cosas, eventos, actores, procesos, escenarios y situaciones dentro de unas categorías determinadas, lo que se lleva a cabo por agregación y comparación". En consecuencia, se seleccionaron las categorías que más se repiten para la confección de ítems representativos de esta información, los que fueron incluidos en los cuestionarios respectivos.

En la sección cuantitativa, la regresión lineal múltiple se utilizó para determinar la relación entre las variables centrales del estudio. Por ejemplo, la relación entre pertenencia como dimensión de la variable sentido de comunidad, y recursos para afrontar la delincuencia, dimensión de percepción de inseguridad.

El Análisis de regresión múltiple consideró como factores a cada dimensión de la variable sentido de comunidad, considerando la hipótesis de investigación que supone la existencia de dimensiones del sentido de comunidad que se presentan como predictoras de las dimensiones de la percepción de inseguridad, entre los habitantes de la población Carlos Trupp y Villa San José de la Florida.

La prueba T se utilizó para contrastar la diferencia de medias en ambos barrios. El estadístico T de Student es una prueba que permite evaluar si dos grupos difieren entre sí, de manera significativa respecto a sus medias, lo que en el caso de esta investigación es de suma utilidad al contrastar las hipótesis de investigación.

Por último, se menciona que en las pruebas estadísticas se cumplió con los supuestos de normalidad, homocedasticidad y linealidad. 


\section{RESULTADOS}

\subsection{Descripción cualitativa de percep- ciones de inseguridad y sentido de comunidad}

\section{Sentido de pertenencia con el barrio}

Es posible describir el sentirse parte y compartir con las personas del barrio como "importante" $y$ "muy importante" por ambos barrios (Tabla 3)
Un alto porcentaje de los encuestados llama "villa" al sector en que vive, en una observación de la muestra en general. Sin embargo, al analizar los sectores por separado se aprecia que Carlos Trupp llama mayoritariamente "población" al lugar donde vive, mientras que San José, opta por "viIla". Siendo de este modo "barrio" la opción menos preferida.

Tabla n ${ }^{\circ}$. Importancia de sentirse parte y compartir con las personas del barrio, población Carlos Trupp y Villa San José de La Florida.

\begin{tabular}{|l|c|c|c|c|c|c|}
\hline Preferiría no ser parte & 3 & 50,0 & 3 & 50,0 & 6 & 2,9 \\
\hline Nada importante & 3 & 42,9 & 4 & 57,1 & 7 & 3,4 \\
\hline No muy importante & 13 & 54,2 & 11 & 45,8 & 24 & 11,7 \\
\hline Algo importante & 10 & 32,3 & 21 & 67,7 & 31 & 15,1 \\
\hline Importante & 34 & 39,1 & 53 & 60,9 & 87 & 42,4 \\
\hline Muy importante & 22 & 44,0 & 28 & 56,0 & 50 & 24,4 \\
\hline & Frecuencia & & Frecuencia & & 205 & 100,0 \\
\hline & Barrio 1 & & Barrio 2 & & & \\
\hline
\end{tabular}

Fuente: Elaboración propia.

\section{Participación en el barrio}

Los participantes asignan una alta valoración a la participación; sin embargo, se perciben barreras para ejercerla cuando ésta se relaciona con temas de seguridad. Se percibe en ambos barrios desconocimiento respecto a "la directiva", desconfianza en los procedimientos de toma de decisiones, desinformación y confusión respecto a elección de directivas. Se observa temor a la petición de información sobre rendición de cuentas. Al mismo tiempo, se percibe un involucramiento activo de los dirigentes vecinales en asuntos del barrio, lo que no se relaciona con una mayor participación de los vecinos. Se asocia la participación con la postulación a beneficios de reconstrucción y otros programas, no existiendo una participación sostenida a través del tiempo. Se describe un estilo de participación circunstancial, transitoria e instrumentalizada por parte de los encargados de programas sociales.

Uso comunitario de alarmas y sentido de pertenencia

Los usos dados a las alarmas comunitarias en ambos barrios no están asociados únicamente a seguridad. Se describe su utilidad para emergencias médicas, la evitación y alerta 
ante personas extrañas al sector y la creencia de que están asociadas a sistemas de resguardo policial.

Desde la puesta en marcha del sistema de alarmas, es posible identificar como consecuencias percibidas por los vecinos las siguientes: conocimiento entre vecinos desconocidos, aumento de confianza entre ellos, cuidado recíproco de los hogares y tendencia a percibir una sensación subjetiva de seguridad. La instalación de las alarmas comunitarias estuvo asociada al aumento de la frecuencia de contacto vecinal, producto de las reuniones para su instalación.

Las personas valoran las reacciones instantáneas de los vecinos ante las alarmas, descritas como de urgencia, rapidez y disposición a ser despertados a altas horas de la noche. Sin embargo, se señala el proceso de transformación que experimentaron, desde un estilo individualista de cuidado a uno de carácter colectivo.

Habitante población Carlos Trupp, Mujer "... Sí...costó mucho para que la gente entendiera que no era vivir el metro cuadrado o sea cuesta hacer entender al vecino que sí dependemos uno del otro. Así que no somos tan solo solitos, porque muchas veces tenemos que depender, aunque (no lo) queramos, en algún minuto dependemos del vecino. Entonces, la idea era de hacerles creer y sentir que eran parte del vecino y del resto. Costó, pero entendieron...entendieron que esto se trabaja en conjunto, que de a uno no se puede, solo no se puede trabajar...."
Lo descrito puede reflejar el proceso de construcción colectiva de la mutua influencia y la satisfacción de necesidades, componentes insertos dentro de las dimensiones del sentido de comunidad.

\section{La estructura de pasajes y la satisfac- ción de necesidades}

Se describe una práctica usual al interior de los barrios. Esta se relaciona con la saliencia de la estructura relacional a nivel de pasajes, distinto al concepto de comunidad territorial barrial, cuya dispersión y distancia impiden un acercamiento más sostenido entre vecinos. Sin embargo, esta ausencia se reemplaza con la valoración que recibe la vinculación y la conexión emocional con los vecinos "del pasaje", quienes generan conductas de reciprocidad y cooperación en un nivel intermedio.

Habitante San José, Hombre ".. mira, yo te voy a contar algo que en cada pasaje está pasando, también en el mío pasa esto. Nos juntamos una vez a la semana, los vecinos, y nos ponemos a hacer un plan de trabajo iya! El vecino que...supongamos, yo salgo de mi casa y no le aviso al vecino que voy a salir, pero el vecino está en conocimiento que prácticamente yo no estoy en las mañanas, todos los vecinos conocen que yo no estoy en las mañanas, al lado sabemos que tenemos una persona enferma y el del frente debe preocuparse de que esa vecina deba estar bien. O sea, si él siente que tocan el aparatito, él sabe ya que esa vecina está enferma y lo que necesita. Así se trabaja en el tema de las alarmas. Si yo voy a salir de vacaciones, ya mi cuadra 
completa sabe que voy a salir de vacaciones y ellos se van a preocupar de que esto esté cerradito..."

Se observa una tendencia a confiar en los vecinos "del pasaje" porque en ellos es posible depositar mayor confianza para el cuidado de la casa.

Grupo focal Carlos Trupp, "sucede que...mira, tú, de partida, tienes que dar la confianza, porque sí tú creas desconfianza, este tema de las alarmas no funcionaría jamás. Aquí va la confianza que tú tengas en tus vecinos, una confianza compartida que todos...al menos no de la calle, acá yo te estoy hablando de mi pasaje; por lo menos son todas personas adultas, no tenemos jóvenes, son muy pocos y los que están...están fuera. Entonces, son vecinos de años. Es muy difícil que un vecino le diga a otra persona que la casa está sola, sabiendo que él está a cargo de la casa de al lado. Yo voy a ser responsable si a mi vecina le entran a robar, sabiendo que ella no está, voy a ser tan responsable como la dueña de casa. O sea, nos hacemos un compromiso. Ese compromiso, yo te digo, se respeta hasta el último."

\subsection{Descripción resultados sección cuantitativa.}

\section{Percepción de inseguridad según ba- rrio de residencia}

En la opción de respuesta "totalmente de acuerdo", en la Población Carlos Trupp, la concentración más alta se encuentra en el ítem tranquilidad con mejor iluminación y seguridad cuando vecino vigila la casa. El primer ítem podría estar asociado con la antigüe- dad de la población y su extensión territorial, lo que da cuenta de sitios eriazos o luminarias defectuosas que influyen en que las personas consideren la iluminación como un factor que fortalecería la seguridad en el barrio. Las personas se sienten más seguras cuando existe mayor cohesión entre los vecinos de un mismo pasaje, de acuerdo a los testimonios recogidos entre los pobladores en el estudio cualitativo previo.

En la Villa San José de la Florida, la opción seguridad cuando vecino vigila la casa es el ítem con frecuencia de menciones más elevado, seguido de comunicación con carabineros es importante. De la misma forma que en la Carlos Trupp, se puede apreciar la relevancia que le dan los habitantes de este barrio a los recursos para afrontar la delincuencia. Sin embargo, a diferencia de los pobladores del sector oriente, en "la villa" le dan mayor jerarquía a la gestión de la policía uniformada por sobre el factor luminarias.

A diferencia de lo anterior, la opción "en desacuerdo" concentra altos porcentajes de respuesta en el ítem la delincuencia ha disminuido en ambas poblaciones (Gráfico 1) 
Gráfico n¹. Percepción de inseguridad según lugar donde vive.

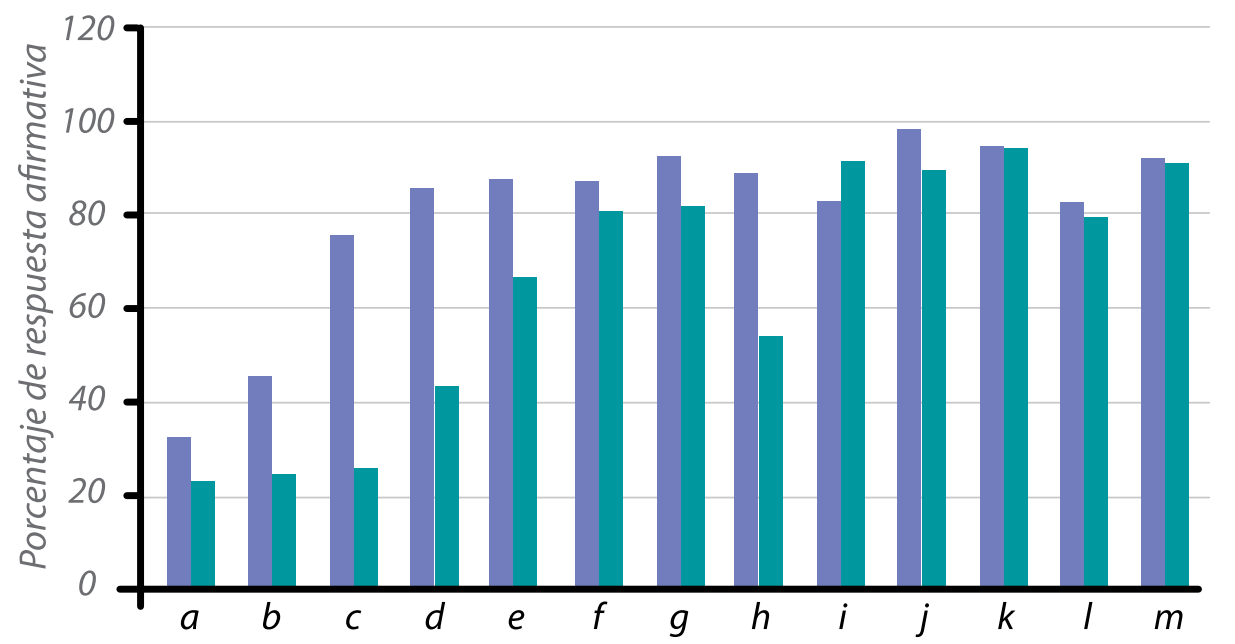

Carlos Trupp

a. Delincuencia ha disminuído

b. Dejar actividades

c. Evitar lugares

d. Evitar lugares oscuros

e. Evito acercarme a extraños

f. Me siento seguro con la alarma

g. Necesidad de alarma

\section{San José}

h. Temor sector menos iluminado

i. Carabineros me da seguridad

j. Más tranquilidad con mejor iluminación

k. Vecinos y carabineros comunicados...

I. Tranquilidad cuando mi vecino...

$m$. Siento seguridad cuando mi hogar está vigilado

Fuente: Elaboración propia. 


\section{Sentido de comunidad según barrio de residencia}

En relación al sentido de comunidad, la opción de respuesta "totalmente en desacuerdo" y "en desacuerdo" que distingue a ambas poblaciones, se concentra en el ítem se preocupa por opinión de vecinos. A diferencia de en el barrio se siente como en casa, buena convivencia entre vecinos y conocimiento de vecinos más cercanos que se agrupan en la opción "totalmente de acuerdo" y "de acuerdo" (Gráfico 2).

Gráfico n². Sentido de comunidad según lugar donde se vive.

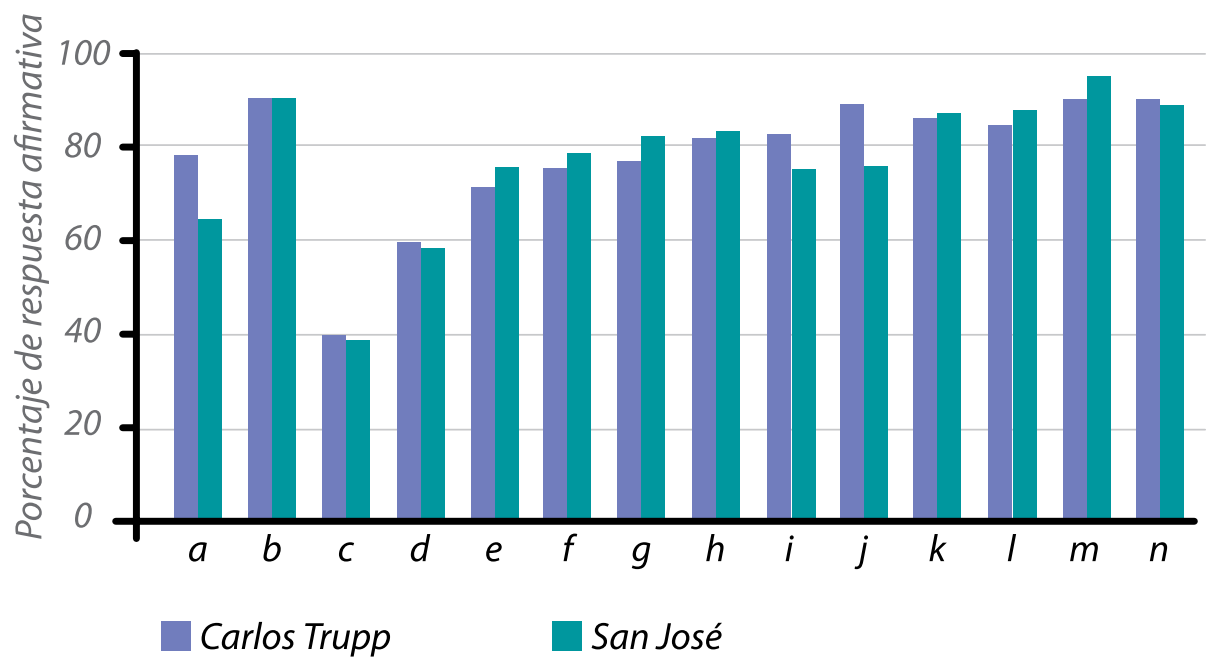
a. Reconoce a la mayoría de...
h. Espera seguir viviendo allí
b. En el barrio me siento como... $i$.
c. Se preocupa por la opinion de...
j. Confianza en respaldo de...
d. Puede influir en población
k. Vecinos acudiran en ayuda
e. Pobladores resuelven sus...
l. Gratificación por participación
f. Importancia de vivir en... $m$.
g. Buena convivencia con vecinos... n. Alarma permite alertar $a . .$.

Fuente: Elaboración propia. 


\section{Contraste de Hipótesis}

A continuación se detallan las hipótesis de la investigación, con una breve descripción de su planteamiento y los resultados asociados a las pruebas estadísticas efectuadas. Cabe reiterar que se cumple con los supuestos de linealidad, homocedasticidad y normalidad para las pruebas de regresión múltiple.

Hipótesis 1. Nuestra primera hipótesis plantea que las variables de estudio se presentan con diferentes niveles en ambas poblaciones, de acuerdo a sus dimensiones pertenencia, influencia y territorialidad (en sentido de comunidad) así como de la percepción de inseguridad en el barrio y recursos para afrontar la delincuencia (en percepción de inseguridad). En relación a sentido de comunidad, la primera de sus dimensiones se observaría con mayor intensidad en Carlos Trupp y las dos últimas serían semejantes en los dos barrios. Los resultados exponen que no existen diferencias significativas entre las dimensiones en ambas poblaciones. Por lo tanto, se deja en evidencia que la media para las dimensiones de pertenencia, influencia y territorialidad logra niveles semejantes en la población Carlos Trupp y la San José de La Florida, tal como se muestra a continuación, en la Tabla; es decir, las tres dimensiones de la variable independiente se presentan con similar intensidad en ambas poblaciones.

Tabla nº 4 . Comparación de medias respecto al sentido de comunidad, ambos barrios.

\begin{tabular}{|c|l|c|c|c|c|} 
DIMENSIÓN & \multicolumn{1}{c}{$\begin{array}{c}\text { M } \\
\text { media }\end{array}$} & $\begin{array}{c}\text { t } \\
\text { valor de } \\
\text { prueba }\end{array}$ & $\begin{array}{c}\text { GI } \\
\text { grados de } \\
\text { libertad }\end{array}$ & $\begin{array}{c}\text { Sig. } \\
\text { (bilateral) } \\
\text { probabilidad } \\
\text { de error }\end{array}$ \\
\hline \multirow{2}{*}{ Pertenencia } & Carlos Trupp & 3,092 & 0,83 & 224 & 0,407 \\
\cline { 2 - 7 } & San José & 3,030 & & \\
\hline \multirow{2}{*}{ Influencia } & Carlos Trupp & 2,660 & 0,83 & 224 & 0,403 \\
\cline { 2 - 7 } & San José & 2,578 & & & \\
\hline \multirow{2}{*}{ Territorialidad } & Carlos Trupp & 3,234 & 0,34 & 224 & 0,733 \\
\cline { 2 - 6 } & San José & 3,206 & \multicolumn{4}{|c|}{} \\
\hline
\end{tabular}

Fuente: Elaboración propia. 
Respecto a percepción de inseguridad, existen diferencias significativas en esta dimensión $t(224)=7,854 p=$ $0,000)$. En cambio, la dimensión recursos de afrontamiento no presenta diferencias significativas t (224) 1,859, $p=0,066$. En relación a las medias de ambas poblaciones, Carlos Trupp presenta las más elevadas. Esto se exhibe en la tabla a continuación (Tabla 5). De acuerdo a lo anterior, percepción de inseguridad en el barrio se presenta con mayor intensidad en el barrio Carlos Trupp, pero recursos para afrontar la delincuencia es similar en ambas poblaciones.

Tabla ${ }^{\circ} 5$. Comparación de medias respecto a la percepción de inseguridad, ambos barrios.

\begin{tabular}{|c|c|c|c|c|c|}
\hline \multicolumn{2}{|l|}{ DIMENSIÓN } & $\underset{\text { media }}{\mathbf{M}}$ & $\begin{array}{c}\mathbf{t} \\
\text { valor de } \\
\text { prueba }\end{array}$ & $\begin{array}{c}\text { GI } \\
\text { grados de } \\
\text { libertad }\end{array}$ & $\begin{array}{c}\text { Sig. } \\
\text { (bilateral) } \\
\text { probabilidad } \\
\text { de error }\end{array}$ \\
\hline \multirow{2}{*}{$\begin{array}{l}\text { Percepción de } \\
\text { inseguridad }\end{array}$} & Carlos Trupp & 3,092 & 7,85 & 224 & $* * 0,000$ \\
\hline & San José & 2,426 & & & \\
\hline \multirow{2}{*}{$\begin{array}{l}\text { Recursos para } \\
\text { afrontar la } \\
\text { delincuencia }\end{array}$} & Carlos Trupp & 3,474 & 1,85 & 224 & 0,066 \\
\hline & San José & 3,323 & & & \\
\hline
\end{tabular}

Fuente: Elaboración propia.

${ }^{*}$ significativo al 0,05 
Hipótesis 2. La segunda hipótesis sostiene que existen dimensiones del sentido de comunidad que logran predecir las dimensiones de la percepción de inseguridad. Esto significa la determinación del poder de la variable sentido de comunidad y sus dimensiones para explicar la variabilidad de la percepción de inseguridad ante el delito.

Para conocer esta relación de influencia, se aplicó un modelo de regresión múltiple. Este permite determinar la contribución única o parcelada de las variables independientes a la variable dependiente, en el contexto de las demás variables del modelo. De esta manera se hace cargo de la multicolinealidad de las variables independientes (Cohen \& Cohen, 2003, citado en Martínez \& Silva, 2007). El modelo permite determinar el aporte único de las dimensiones pertenencia, influencia y territorialidad a la percepción de inseguridad y recursos para afrontar la delincuencia, de modo de contrastar la hipótesis.

\section{Sentido de Comunidad sobre percep- ción de inseguridad en el barrio}

Las dimensiones pertenencia, influencia y territorialidad no son predictivas, por sí mismas, de la dimensión percepción de inseguridad en el barrio. Ninguna de las tres dimensiones explica la varianza de la percepción de inseguridad. Pertenencia (R2 $=0,000)$ sin significación, $F(1,224)=$ $0,78, p=0,376$. Influencia $(R 2=0,012)$ sin significación, $F(1,224)=3,63, p$ $=0,058$. $Y$ territorialidad $(R 2=0,005)$ sin significación, $F(1,224)=2,19, p=$ 0,140 . Tanto la pertenencia $(\beta=0,59$, $p=0,376)$ como influencia $(\beta=0,12$, $p=0,058)$ y territorialidad $(\beta=0,09, p$ $=0,140$ ) no demuestran efectos significativos en la percepción de inseguridad en el barrio. La Tabla 6 ilustra los coeficientes del modelo.

Tabla n $^{\circ}$. Modelo de regresión sentido de comunidad sobre percepción de inseguridad. ${ }^{23}$

\begin{tabular}{|l|c|c|c|c|c|c|c|}
\hline PREDICTOR & $\mathbf{R}^{2}$ & gl & F & sig. & Tol. & FIV & $\boldsymbol{\beta}$ \\
\hline Pertenencia & 0,000 & $1 / 224$ & 0,786 & 0,376 & 1,0 & 1,0 & 0,59 \\
\hline Influencia & 0,012 & $1 / 224$ & 3,637 & 0,058 & 1,0 & 1,0 & 0,12 \\
\hline Territorialidad & 0,005 & $1 / 224$ & 2,198 & 0,140 & 1,0 & 1,0 & 0,09 \\
\hline
\end{tabular}

Fuente: Elaboración propia.

\footnotetext{
23 R2= Coeficiente de determinación. Porcentaje de la varianza de percepción de inseguridad explicado por las VI (variables independientes). Entre más cercano a 1, mayor \% varianza explicada.

$\mathrm{gl}=$ grados de libertad

$\mathrm{F}=$ razón $\mathrm{F}$

Sig= significación estadística. Probabilidad de error

Tol= valor de tolerancia (valores próximo a 0 , indican multicolinealidad)

FIV $=$ factor de inflación de la varianza (valores superiores a 4 denotan multicolinealidad)

$\mathrm{B}=$ pesos estandarizados. Incremento de la VD (variable dependiente) al aumentar en una unidad la VI (variable independiente)
} 
Sentido de Comunidad sobre recursos para afrontar la delincuencia

De la misma forma que en el análisis anterior, se puede observar que las dimensiones de la variable sentido de comunidad no constituyen un buen predictor de la dimensión recursos para afrontar la delincuencia, cuando éstas se analizan como factores independientes. Es así como se demuestra en la Tabla 7, en donde se desarrollan dos modelos que aportan de manera progresiva a la explicación de la varianza.

Inicialmente se presentan las tres dimensiones de la variable independiente de manera separada (Modelo I). Las dimensiones pertenencia (R2= $0,07)$ significativa con $F(1,224)=18,94$, $\mathrm{p}=0,000$; influencia $(R 2=0,16)$ significativa con $F(1,224)=43,99, p=0,000$; y territorialidad $(R 2=0,19)$ significativa con $F(1,224)=54,93, p=0,000$, poseen un poder predictivo menor.
Pertenencia $(\beta=0,27, p=0,000)$, influencia $(\beta=0,40, p=0,000)$ y territorialidad $(\beta=0,44, p=0,000)$ explican la varianza en un porcentaje bajo y medio. Sin embargo, cuando son integrados en un modelo global, explican un mayor porcentaje de recursos para afrontar la delincuencia.

El modelo que incluye las dimensiones territorialidad e influencia de forma conjunta constituye un mejor predictor para la dimensión recursos para afrontar la delincuencia (Modelo II) que sus predictores por separado. Este modelo explica casi un tercio de la varianza de recursos para afrontar la delincuencia $(R 2=0,27)$ siendo significativo, $F(2,223)=43,53, p=0,000$. Tanto la territorialidad $(\beta=0,30$, $p=0,000)$ como la influencia $(\beta=0,35$, $p=0,001)$, demostraron efectos significativos en los recursos para afrontar la delincuencia.

\section{Tabla n7. Modelos de regresión sentido de comunidad sobre recursos para afrontar la} delincuencia.

\begin{tabular}{c|l|c|c|c|c|c|c|c|}
\hline MODELO & \multicolumn{1}{l}{ V.I } & \multicolumn{1}{c}{$\mathbf{R}^{2}$} & \multicolumn{1}{c|}{ gl } & \multicolumn{1}{c|}{ sig. } & \multicolumn{1}{c|}{ Tol. } & \multicolumn{1}{c|}{ FIV } & $\boldsymbol{\beta}$ \\
\hline $\begin{array}{c}\text { I Rec. } \\
\text { afront. } \\
\text { del. }\end{array}$ & Pertenencia & 0,07 & $1 / 224$ & 18,94 & 0,000 & 1,0 & 1,0 & 0,27 \\
\cline { 2 - 9 } & Influencia & 0,16 & $1 / 224$ & 43,99 & 0,000 & 1,0 & 1,0 & 0,40 \\
\hline $\begin{array}{c}\text { II Rec. } \\
\text { afront. } \\
\text { del. }\end{array}$ & $\begin{array}{l}\text { Influencia } \\
\text { derritorialidad }\end{array}$ & 0,27 & $2 / 223$ & 43,53 & 0,000 & 0,91 & 1,09 & 1,87 \\
\hline
\end{tabular}

Fuente: Elaboración propia. 
Lo anterior implica que cuando se analizan influencia y territorialidad de manera conjunta, se puede determinar la variabilidad de los recursos para afrontar la delincuencia. Esto no implica una relación causal, pero sí un potencial explicativo de las variaciones que experimenta entre las personas la percepción de recursos para afrontar la delincuencia. Esto quiere decir que si se evalúa la influencia mutua entre vecinos y la percepción de sentido de territorio (pasaje), se puede comprender de mejor forma la percepción que tienen los vecinos sobre los recursos para afrontar la delincuencia. Esto puede tener importantes consecuencias sobre el diseño de estrategias de intervención, para que se focalicen en el trabajo con estas dos dimensiones al interior de los barrios.

\section{V.DISCUSIÓN}

Los hallazgos de este estudio ilustran la importancia de evaluar no solo los componentes residenciales objetivos de la percepción de la delincuencia, sino también aquellos factores de naturaleza relacional y simbólica.

Este estudio destaca la valoración que los vecinos asignan a las alarmas comunitarias, no solo como un mecanismo protector ante el delito, sino como una herramienta que ha facilitado la proximidad física, relacional, la conexión emocional compartida y el sentido de pertenencia entre los vecinos de los diferentes pasajes.

Se reporta que el sentido de comunidad no difiere entre barrios con características diferentes. Sin embargo, estos sí se diferencian en sus niveles de percepción de inseguridad. El sentido de comunidad (tanto la mutua influencia entre vecinos como la territorialidad) aporta en la predicción de la percepción de recursos para prevenir la delincuencia.

Un primer foco de discusión se relaciona con la importancia atribuida a la participación comunitaria en estos proyectos. A pesar que en el planteamiento de todos los programas y políticas en seguridad ciudadana, se visualiza la participación comunitaria como un valor y una estrategia de desarrollo, es necesario vislumbrar el concepto de participación que se sostiene. Más que concebirla desde una posición instrumental, debería transformarse en un elemento unificador, y de desarrollo de procesos de empoderamiento barrial, que faciliten el control ciudadano. Las comunidades, barrios y personas, pueden percibir una mayor percepción de control sobre sus entornos, y por ende aumento de participación en su seguridad. Esto impone desafíos en la forma de diseño e implementación de programas y proyectos futuros.

La participación otorga legitimidad a las políticas públicas, generando efectos importantes que van más allá del cumplimiento de metas. Involucra la visión de una ciudadanía activa, protagonista y decisora. Ejemplo de ello es el caso de los habitantes del sector Santos Martínez en la comuna de Curicó, Región del Maule, quienes a partir de la movilización lograron influir en que se hicieran cambios profundos en la política de vivienda. Lograron modificar prácticas guber- 
namentales que derivaron en el desarrollo de viviendas a partir de diseños participativos, el mejoramiento de la infraestructura urbana $y$, de manera principal, la mantención del sentido de pertenencia a sus barrios.

Este estudio pretende contribuir a la reflexión sociopolítica respecto al papel de los medios de comunicación, las agendas de gobierno y la sociedad del miedo que reproduce la sensación de vulnerabilidad permanente. Constituye una paradoja que el sistema económico tienda a reproducir las distancias sociales a través de barrios cada vez más protegidos artificialmente del delito y que por esta vía se disminuya la interacción, reciprocidad, mutua influencia y la satisfacción de necesidades comunes, todos ellos factores clave del sentido de comunidad. De ahí la importancia de generar estrategias preventivas a nivel municipal, que logren evaluar cómo y en qué medida los barrios se constituyen en comunidad y no en un mero agregado social residencial.

Propuesta para el diagnóstico y evaluación de impacto de programas y proyectos de seguridad preventiva a nivel municipal

El sentido de comunidad podría servir como indicador que permita evaluar el impacto psicosocial de este tipo de programas preventivos en cada uno de los barrios en donde las municipalidades los ejecutan. Esto facilitaría la evaluación en todo el ciclo del proyecto, pero sobre todo, permitiría hacer estudios ex ante y ex post que determinen los efectos e impactos de este tipo de proyectos y programas sobre las comunidades. Adicionalmente, las percepciones de las personas pueden ser integradas como una dimensión territorial de este sentido de comunidad, en cada uno de barrios donde se ejecutan los programas. Esto facilitará la adecuación y pertinencia a las características socioculturales y relacionales del barrio.

Para las municipalidades, constituye un desafío disponer de instrumentos estandarizados que faciliten la operacionalización adecuada del impacto comunitario de estos programas (Prezza, Pacilli, Barbaranelli, \& Zampatti, 2009). Otros conceptos y procesos, tales como eficacia colectiva, sentido de agencia y empoderamiento, también podrían ser de utilidad para los programas preventivos.

Así se respondería la pregunta ¿Cambian las comunidades una vez que se implementa este tipo de proyectos? ¿Las modificaciones en sus sentidos de comunidad pueden ser consideradas indicadores de impacto de programas que fortalezcan la seguridad percibida? ¿Estos cambios serán impulsores de nuevos procesos de transformación comunitaria? 


\section{Limitaciones del estudio}

Dado que no se empleó un muestreo probabilístico, los hallazgos de este estudio deben contextualizarse adecuadamente para la comprensión de otros barrios, por el efecto de autoselección de los participantes.

Adicionalmente, la mayor proporción de participantes de género femenino pudo generar efectos sobre la interpretación y generalización de los hallazgos.

Otro elemento limitante fue el uso de unidades de observación individual para variables de naturaleza relacional o contextual. Especialmente en el caso del sentido de comunidad, se sugiere el uso de medidas multinivel, que permitan hacer análisis con métodos anidados para capturar mejorar la complejidad relacional del constructo.

Tampoco se incorporaron variables intervinientes de interés para la investigación, como podrían ser el nivel de participación social y la presencia de otros proyectos se seguridad ciudadana que pueden estar relacionados con los niveles de percepción de inseguridad. Finalmente, algunas variables sociodemográficas que no se integraron al análisis como el sexo, edad o nivel socioeconómico, no conformaron parte de los objetivos del estudio.

\section{Fortalezas del estudio}

Éste estudio destaca la importancia de contar con constructos de origen psicológico -comunitario para evaluar programas sociales de prevención de la delincuencia (Peterson et. al., 2008), junto con la promoción de la participación comunitaria en los procesos preventivos (Pérez \& Núñez, 2008).

Futuras investigaciones podrían aportar en la evaluación comunitaria de componentes como el sentido de comunidad, utilizando algunas de sus dimensiones como indicadores de impacto de los programas.

Adicionalmente, se podría disponer de un diagnóstico local y contextual del cambio que se produce en las comunidades producto de la interacción entre estrategias preventivas y la contribución que desarrollan las organizaciones del barrio como agentes preventivos.

Finalmente, podría evaluarse de modo más exhaustivo procesos de empoderamiento barrial y eficacia colectiva, a través de metodologías multinivel. 


\section{REFERENCIAS}

Álvaro, D. (2010). Los conceptos de "comunidad" y "sociedad" de Ferdinand Tonnies. Papeles del CEIC, 52, $1-24$.

Anderson, M. (2010). Community psychology, political efficacy and trust. Political Psychology, 31(1), 59-83.

Brodsky, A., O`Campo, P., \& Aronson, R. (1999). PSOC in community contexts: multi-level correlates of a measure of psychological sense of community in low-income, urban neighborhoods. Journal of Community Psychology, 27(6), 659-679.

Buzó, M. (2011). Influencia del contexto de vida, la participación social y el sentido de comunidad: un estudio en adolescentes chilenos. Tesis de Magister no publicada, Facultad de Ciencias Sociales, Pontificia Universidad Católica de Chile.

Creswell, J., \& Plano-Clark, V. (2007). Designing and conducting mixed methods research. Thousand Oaks, CA: Sage publications.

Dammert, L. (2004). El gobierno de la Seguridad en Chile, 1973-2003. Seguridad ciudadana: experiencias y desafíos. Editorial Red Urbal 14.

Dammert, L. (2007). Percepción y participación. Programa Estudios. Revista Ciudad Segura, (15).

Flick, U. (2004). Introducción a la investigación cualitativa. Madrid: Morata.
Fruhling, H., \& Sandoval, L. (1997). Percepción de inseguridad y realidad delictual en tres comunas populares de Santiago. Estudios Públicos, 68.

Fundación Paz Ciudadana. (2011). Balance de la delincuencia 2010. Santiago: Autor.

Fundación Paz Ciudadana. (2011b). Gestión municipal de la seguridad ciudadana en barrios vulnerables. Estudio exploratorio. Santiago: Autor.

Hombrados-Mendieta, I., Gomez-Jacinto, L., \& Domínguez-Fuentes, J. M. (2009). The impact of immigrants on the sense of community. Journal of Community psychology, 37(6), 671 683.

Kingston, S., Mitchell, R., Florin, P., \& Stevenson, J. (1999). Sense of community in neighborhoods as a multilevel construct. Journal of Community Psychology, 27(6), 681 - 694.

Mannarini, T., \& Fedi, A. (2009). Multiple senses of community: The experience and meaning of community. Journal of Community Psychology, 37(2), 211 - 227.

Silva C \& Martínez M.L. (2007). Empoderamiento, participación y autoconcepto de persona socialmente comprometida en adolescentes chilenos. Revista Interamericana De Psicologia. 41(2), 129-138.

Maya, I. (2004). Sense of community. Obtenido el 27 de noviembre de 2012 de www.senseofcommunity.com 
McMillan, D., \& Chavis, D. (1986). Sense of community: A definition and theory. Journal of Community Psychology, 14, 6 - 23.

Ministerio del Interior y Seguridad Pública. (2010). Síntesis delictual Encuesta Nacional de Seguridad Urbana (ENUSC) - 2010. Santiago: Subsecretaría de prevención del delito.

Ministerio del Interior y Seguridad Pública. (2012). Síntesis delictual Encuesta Nacional de Seguridad Urbana (ENUSC) - 2012. Santiago: Subsecretaría de prevención del delito.

Núñez, Tocornal \& Henríquez. (2012). Determinantes individuales y del entorno residencial en la percepción de seguridad en barrios del Gran Santiago, Chile. Revista INVI, 27(74), 87-120. Oficina comunal de seguridad ciudadana. (2010). Diagnóstico proyecto sistema de alarmas comunitarias, ViIla San José de la Florida. Talca: Autor. Oficina comunal de seguridad ciudadana. (2010). Diagnóstico proyecto sistema de alarmas comunitarias, Población Carlos Trupp. Talca: Autor.

Ohmer, M. (2010). How theory and research inform citizen participation in poor communities: The ecological perspective and theories on self and collective efficacy and sense of community. Journal of Human Behavior in the Social Environment, 20(1), 1 - 19. Pérez, N. y Núñez, G. (2008). "La Participación Comunitaria en la Prevención del Delito: Experiencias recientes en el Área Metropolitana de Caracas". Capítulo Criminológico. Vol. 36, (2).
Peterson, A., Speer, P., Hughey, J., Armstead, T., Shneider, J., \& Sheffer, M. (2008). Community organizations and sense of community: Further development in theory and measurement. Journal of community psychology, 36(6), $798-813$.

Pretty, Conroy, Duguay, Fowler, \& Williams. (1996). Sense of Community and Its Relevance to Adolescents of All Ages. Journal of Community Psychology, 24 (4), 365-379.

Prezza, M., Amici, M., Roberti, T., \& Tedeschi, G. (2001). Sense of community referred to the whole town: Its relations with neighboring, loneliness, life satisfaction and area of residence. Journal of Community Psychology, 29(1), $29-52$.

Prezza, M., Pacilli, M., Barbaranelli, C., \& Zampatti, E. (2009). The MTSOCS: A multidimensional sense of community scale for local communities. Journal of Community Psychology, 37(3), $305-326$.

Prezza, M., Zampatti, E., Pacilli, M., \& Paoliello, A. (2008). Territorial sense of community, ethnic prejudice and political orientation. Journal of Community and Applied Social Psychology, $18,315-338$.

Sandoval, C. (1996). Investigación cualitativa: programa de especialización en teoría, método y técnica de la investigación social. Bogotá: Instituto Colombiano para el fomento de la educación superior ICFES. 
Santillán, A. (2007). Desmitificar la ciudad. Revista Ciudad Segura, (15). Sarason, S. (1974). The psychological sense of community: Prospects for a community psychology. San Francisco: Jossey-Bass.

Skogan, W., \& Maxfield, M. (1981). Coping with crime. Beberly Hills: Sage. Varela, J. \& H. Shwaderer. (2010). Determinantes del temor al delito en Chile. Santiago: Fundación Paz Ciudadana.

Vozmediano, L. (2010). Percepción de inseguridad y conductas de autoprotección: propuestas para una medición contextualizada del miedo al delito. EGUZKILORE, (24), 203-237. 


\section{ANEXOS}

Tabla $\mathbf{n}^{\circ} \mathbf{3}$. Factores de Sentido de Comunidad y cargas factoriales.

\begin{tabular}{|c|c|c|c|}
\hline \multirow{2}{*}{ ITEM } & \multicolumn{3}{|c|}{ Sentido de Comunidad } \\
\hline & Factor 1 & Factor 2 & Factor 3 \\
\hline 1. Creo que mi villa/barrio/ & - & 209 & - \\
\hline 2. La gente de mi villa comparte & 407 & ,764 & 297 \\
\hline 3. Mis vecinos y yo queremos & ,606 & ,423 & ,383 \\
\hline 4. Reconozco a la mayoría de & ,224 & 418 & ,360 \\
\hline 5. En mi población me siento & ,449 & 324 & 275 \\
\hline 6. Muy pocos vecinos me conocen & ,252 & ,226 & ,613 \\
\hline 7. Me preocupa de lo que piensan & ,289 & ,748 & ,237 \\
\hline 8. Puedo influir en como es mi población & 180 & ,787 & 161 \\
\hline 9. Si existiera algún problema la gente de & ,788 & ,475 & 323 \\
\hline 10. Es muy importante para mí vivir en & ,388 & 419 & ,714 \\
\hline 11. Las personas de esta villa se llevan & ,593 & 427 & ,484 \\
\hline 12. Espero vivir en esta villa por un largo & 217 & - & ,896 \\
\hline 13. Muy pocos vecinos participan en las & 110 & 477 & - \\
\hline 14. Mis vecinos participan en las actividades & ,368 & ,699 & ,310 \\
\hline 15. Siento más apoyo de mis vecinos mientras & ,592 & ,377 & ,227 \\
\hline 16. Desde la implementación de las alarmas & ,763 & - & 193 \\
\hline 17. Sí yo activo la alarma comunitaria mis & ,933 & 194 & 318 \\
\hline 18. Siento gratificación al participar de las & 471 & 357 & 467 \\
\hline 19. Conozco más a los vecinos que viven cerca & ,598 & - & ,494 \\
\hline 20. Desde que tengo la alarma siento que puedo &, 505 & 145 & ,602 \\
\hline
\end{tabular}

Fuente: Elaboración propia.

Nota: Se omitieron porcentajes de comunalidades bajas o no significativas 
Tabla ${ }^{\circ}$ 4. Factores de Percepción de Inseguridad y cargas factoriales.

\begin{tabular}{|l|c|c|}
\multicolumn{1}{|c}{ ITEM } & Factor 1 & Factor 2 \\
\hline 1. La delincuencia se ha mantenido &,- 693 & - \\
\hline 2. La gente de mi villa comparte &, 500 &,- 260 \\
\hline 3. Mis vecinos y yo queremos &,- 296 & - \\
\hline 4. Reconozco a la mayoría de &,- 315 &, 178 \\
\hline 5. En mi población me siento & - &, 898 \\
\hline 6. Muy pocos vecinos me conocen &,- 321 &,- 325 \\
\hline 7. Me preocupa de lo que piensan &, 122 &, 698 \\
\hline 8. Puedo influir en como es mi población &, 673 &, 270 \\
\hline 9. Si existiera algún problema la gente de & - &, 663 \\
\hline 10. Es muy importante para mí vivir en &, 571 &, 271 \\
\hline 11. Las personas de esta villa se llevan &, 751 &, 317 \\
\hline 12. Espero vivir en esta villa por un largo &, 663 &, 375 \\
\hline 13. Muy pocos vecinos participan en las &, 204 &, 675 \\
\hline 14. Mis vecinos participan en las actividades &, 120 &, 101 \\
\hline 15. Siento más apoyo de mis vecinos mientras &,- 421 &,- 116 \\
\hline 16. Desde la implementación de las alarmas &, 544 &, 507 \\
\hline 17. Sí yo activo la alarma comunitaria mis &, 600 & - \\
\hline 18. Siento gratificación al participar de las &, 398 & - \\
\hline 19. Conozco más a los vecinos que viven cerca &, 602 & - \\
\hline 20. Desde que tengo la alarma siento que puedo &, 172 &, 310 \\
\hline
\end{tabular}

Fuente: Elaboración propia.

Nota: Se omitieron porcentajes de comunalidades bajas o no significativas 